\title{
Case report of cerebral creatine deficiency syndrome with novel mutation of SLC6A8 gene in a male child in Bangladesh
}

Muhammad Mizanur Rahman ${ }^{\oplus}$ and Kanij Fatema*®

Department of Pediatric Neurology, Bangabandhu Sheikh Mujib Medical University, Dhaka, Bangladesh

Cerebral creatine deficiency syndrome (CCDS) is a disorder where a defect is present in transport of creatine in the brain. Creatine plays an essential role in the energy metabolism of the brain. This is a genetic disorder, autosomal recessive or X linked, characterized by intellectual disability, speech and language delay, epilepsy, hypotonia, etc. Until recently very few number of cases have been reported. Here we report a case of 1.5-year-old boy who had epilepsy (epileptic spasm and generalized tonic clonic seizure), intellectual disability, microcephaly, hypotonia and speech delay. His magnetic resonance imaging of brain showed cortical atrophy and electroencephalography showed burst suppression pattern. The diagnosis was confirmed by clinical exome sequencing which showed novel mutation of SLC6A8+ in exon 9, suggestive of X linked recessive CCDS. The patient was then treated with glycine, L-arginine and creatine monohydrate with multiple antiepileptic drugs.

Key words: Cerebral creatine deficiency syndrome, SLC6A8 protein, Intellectual disability.

\section{Introduction}

The cerebral creatine deficiency syndrome (CCDS) (\# MIM 300352) is inborn error of metabolism which are characterized by an absence or reduced peak of creatine in the brain. Creatine plays an essential role in energy homeostasis in high energy demanding tissues like brain, muscle and kidney $[1,2]$. It is comprised of three disorders. The two of them have defect in the creatine biosynthesis and the third one has the defect in the biotransport of creatine [3].

The human creatine biosynthesis pathway includes only two enzymes; L-arginine: glycine amidino transferase (AGAT), encoded by AGAT (also known as GATM) and guanidino acetate methyl transferase (GAMT), encoded by GAMT. Both AGAT and
GAMT are autosomal recessive disorder. The transport of creatine in the kidney and brain is regulated by a functional creatine transporter (CT1). CT1 is encoded by SLC6A8 gene at Xq28 (\#MIM 300036). CT1 deficiency is the commonest and it is an X linked recessive disorder. It was first identified in 1996 [4].

The clinical features of CCDS are speech and language delay, cognitive delay, autistic behavior and seizure. It is one of the leading cause of intellectual disability in male [5]. We are reporting a case of CCDS. Our case is a boy of one year and six months who presented with global developmental delay, seizure and intellectual disability. On genetic test, our case was diagnosed as of CTI deficiency due to novel mutation of SLC6A8 gene.

The written informed consent was obtained from the patient's guardian.

Received: 15 January 2021, Revised: 2 March 2021, Accepted: 12 March 2021, Published: 30 June 2021

${ }^{*}$ Corresponding author: Kanij Fatema, FCPS, FCPS. (iD https://orcid.org/0000-0002-2465-053X

Department of Pediatric Neurology, Bangabandhu Sheikh Mujib Medical University, Road 10A, Shahbag, Dhaka 1209, Bangladesh.

Tel: +88-01713097751, Fax: +88-028111243, E-mail: mailmonami@gmail.com

Conflict of interest: The authors declare that they do not have any conflicts of interest.

(C) This is an open-access article distributed under the terms of the Creative Commons Attribution Non-Commercial License (http://creativecommons.org/licenses/by-nc/4.0/) which permits unrestricted non-commercial use, distribution, and reproduction in any medium, provided the original work is properly cited.

(c) Copyright 2021 by the Korean Society of Medical Genetics and Genomics 


\section{Case}

This was a one year and six-month-old boy presented with the complaints of frequent seizure since six months of age and delay in development. Seizure was initially in the form of epileptic spasms, occurring in clusters, 4-10 clusters per day, 5-8 spasms in each cluster. The spasm was flexor in nature. It was not precipitated by fever or any other stimuli. He also had delay in almost all domains of development: gross motor, fine motor, cognition and speech. His hearing and vision was intact. With the onset of seizure, there was further regression of motor skill. Gradually at 1 year age, the pattern of seizure changed, he developed generalized tonic-clonic type of seizure occurring 2-4 times daily, persisting for about 1-5 minutes. Family history revealed that, the boy was the only issue of non-consanguineous parents, none of his family members have similar type of illness. He was delivered by caesarean section, there was no perinatal adverse events, he was born in term with average birth weight. He achieved his neck control at 6 month of age, started to bubble monosyllables at 7 month of age. On examination, he had microcephaly, aphathic face, there was no definite dysmorphism (Fig. 1). His vitals were stable, no cutaneous mark was found. In neurological examination, he had generalized hypotonia, muscle power was 3/5 in all 4 limbs, deep tendon reflexes were preserved and there was extensor planter response. Developmental assessment; gross motor: he only had partial control of neck $(<3$ months), fine motor: could not reach to toys or hold any object ( $<4$ months), speech: only cooing, no babbling ( $<3$ months), cognition: could not recognize mother, only social smile present (around 2 months), vision: fix and follow was present, hearing: startles with sound, could not localize sound.

\section{Investigation}

Magnetic resonance imaging (MRI) of brain showed cortical atrophy with periventricular hyperintensity (Fig. 1B). EEG showed poverty of normal activity in the background, burst suppression pattern (burst of epileptic discharges for 1-3 seconds followed by attenuation): suggestive of epileptic encephalopathy.

\section{Genetic test}

The genetic test was done by next generation sequencing (NGS). Selective capture and sequencing of the protein coding regions of the genome/genes were performed. Due to financial constrain, genetic test of the parents could not be done.

DNA extracted from blood was used to perform targeted gene capture using a custom capture kit. The libraries were sequenced to mean $>80-100 X$ coverage on Illumina sequencing platform. The Genome Analysis Toolkit (Broad Institute Inc., Cambridge, MA, USA) best practices framework was followed for identification of variants in the sample using Sentieon (v201808.07; Sentieon Inc., San Jose, CA, USA). The sequences obtained were aligned to human reference genome (GRCh38.p13) using Sentieon aligner and analyzed using Sentieon for removing duplicates, recalibration and re-alignment of indels [6].

Sentieon haplotype caller has been used to identify variants which are relevant to the clinical indication. Gene annotation of the variants was performed using variant effect predictor program against the Ensembl release 99 human gene model $[7,8]$. In addition to single-nucleotide variants and small indels, copy number variants (CNVs) were detected from targeted sequence data using the ExomeDepth (v1.1.10) method [9]. This algorithm detects rare CNVs based on comparison of the read-depths of

A

$\mathrm{B}$

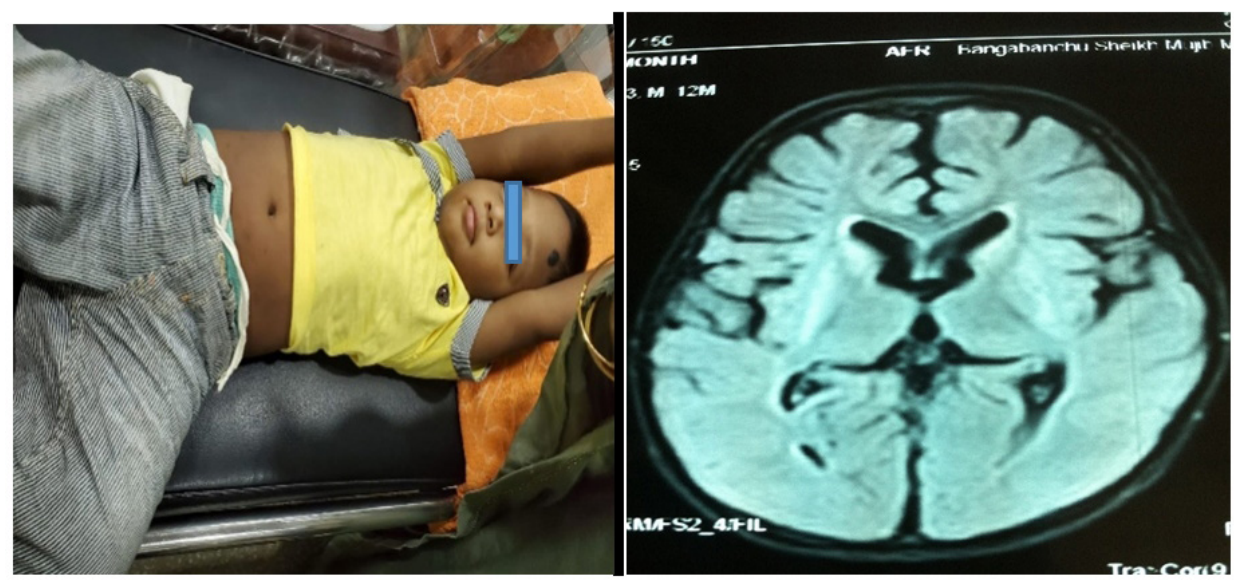

Fig. 1. (A) A male child with cerebral creatine deficiency syndrome. (B) Magnetic resonance imaging of brain showing cortical atrophy. 
the test data with the matched aggregate reference dataset.

Clinically relevant mutations were annotated using published variants in literature, and a set of disease databases - ClinVar, Online Mendelian Inheritance in Man (updated on 20th Feb 2020), Genome-wide association study, Human Gene Mutation Database (v2019.4) and SwissVar [10]. Silent variations that do not result in any change in amino acid, in the coding region, were not reported.

NGS showed mutation of SLC6A8 in exon 9 of chromosome X (variant c. $1319 \mathrm{G}>\mathrm{A}$ (P.Arg440His), hemizygos in pattern suggestive of CCDS which is an $X$ linked recessive disorder (DNA sequence change: c.1319 G>A, amino acid change: P.Arg440His, site of mutation: X chromosome, exon 9, type of mutation: missense).

The boy was treated with various antiepileptic drugs: vigabatrin, topiramate, sodium valproate, levetiracetum, clonazepam, etc. With the above drugs he was seizure was controlled. He was also supplemented with glycine, L-arginine and creatine monohydrate. He was offered physiotherapy, occupational therapy and speech therapy. The parents were counseled regarding the future pregnancy risk.

\section{Discussion}

CCDS is a group of inborn errors of creatine synthesis and transport. AGAT and GMAT deficiency are inherited as autosomal recessive pattern and CT1 deficiency is inherited as $X$ linked recessive disorder. The hallmarks of CCDS are mental retardation, delay in speech and epilepsy. There are also some behavioral disorders like hyperactivity and autistic features. Some cases of the CCDS are associated with movement disorders due to basal ganglia involvement. This is more common in GAMT deficiency $[1,11]$.

CT1 deficiency which is due to mutation of $S \angle C 6 A 8$ was first reported in a 6-year-old boy presented with central hypotonia, epilepsy, speech delay and intellectual disability. The seizure was in the form of status epilepticus. The case was confirmed by genetic diagnosis: hemizygos mutation of SLC6A8 mutation [12]. Our case has all the similarities with the above mentioned case. This case was diagnosed early due to the advent of the genetic tests. Moreover, our case had microcephaly which was absent in this case.

In one report, authors have mentioned 142 SLC6A8 variants in 667 individuals in western population. About 30\% mutations were de novo and 70\% were maternally inherited [13]. The frequency of CCDS in male with intellectual disability was about $1.5 \%$ a paper by Clark et al. [14].
In the reported cases of CCDS, the clinical features were intellectual disability, expressive speech and language delay, epilepsy, developmental delay and autistic behavior. Other uncommon features were muscular hypotonia, hyperextensible joints, movement disorders, short stature, dysmorphism, etc. With the advance of the age the neurological and psychiatric manifestations may progress $[11,15]$. Wang et al. [16] reported gastrointestinal problems such as chronic constipation or nausea in CCDS. Our case had all the features except constipation. Moreover, microcephaly was noted in our case which was not found in any reported case. Regarding the pattern of the epilepsy, the types of the seizure mentioned are generalized tonic clonic seizure, status epilepticus, drug resistant epilepsy and frontal lobe epilepsy [17]. The type of seizure in our case was initially infantile spasm and generalized tonic clonic seizure which was difficult to control and multiple antiepileptic drugs have been used to control the seizure.

There are certain biochemical changes in CCDS evidenced by complete or partial lack of creatine in the brain, muscle and kidney. The most significant deficit is observed in brain [18]. Brain proton magnetic resonance spectroscopy ( $\left.{ }^{1} \mathrm{H}-\mathrm{MRS}\right)$ is an important investigation for diagnosis of CCDS but it is not available in all centers and costly $[1,2]$. MRI of brain which showed atrophy, brain ${ }^{1} \mathrm{H}-\mathrm{MRS}$ was not done due to lack of logistic support. The muscle creatine is determined by muscle biopsy. Urinary creatine/creatinine ratio has also been found as a useful diagnostic marker of SLC6A8 deficiency in males [2]. These tests were not done in our case.

The confirmation of diagnosis is done by demonstration of enzyme activity, determination of transporter activity in fibroblast or lymphoblast or DNA analysis of the gene [19]. We confirmed the case with clinical exom sequencing which revealed there was hemizygos mutation of $S \angle C 6 A 8$ gene in exon 9.

The treatment of SLC6A8 deficiency does not match with that of GAMT and AGAT where creatine supplementation is the mainstay of treatment [19]. Rather CT1 deficiency disorder is treated with supplementation with high doses of L-arginine and L-glycine, which are the primary substrates for creatine biosynthesis, combined with high doses of creatine monohydrate. This combination is given with an aim to increase intracerebral creatine synthesis [20]. Other modalities of treatment in practice are supplementation of L-arginine alone, facilitate the creatine transport in the brain via carrier peptides or molecules [19]. We treated our patient with the combination of L-arginine, L-glycine and creatine along with the supportive management and antiepileptic drugs. Due to financial constraint parents could not be evaluated 
by genetic tests. However, there was no clinical feature suggestive of CCDS among parents and other members in the family.

CCDS is a rare disorder, yet it is an important cause of intellectual disability and under-recognized. However, it is a potentially treatable condition, thus early detection is important for the favorable outcome. Prenatal diagnosis is another important option to address in case of positive family history. Our case is probably the first case from Bangladesh with CCDS with mutation of SLC6A8 gene.

\section{Acknowledgements}

The authors thank Dr. Maya Thomas, Professor and Head, Pediatric Neurology, Christian Medical College for treating physician, MedGenome Lab for genetic test, Shaiyan Imrul and Saishi Rupkotha Imrul for grammatical correction and revising.

\section{Authors' Contributions}

Conception and design: MMR. Acquisition of data: KF. Analysis and interpretation of data: MMR. Drafting the article: KF. Critical revision of the article: MMR. Final approval of the version to be published: KF.

\section{References}

1. Stockler S, Schutz PW, Salomons GS. Cerebral creatine deficiency syndromes: clinical aspects, treatment and pathophysiology. Subcell Biochem 2007;46:149-66.

2. Comeaux MS, Wang J, Wang G, Kleppe S, Zhang WW, Schmitt ES, et al. Biochemical, molecular, and clinical diagnoses of patients with cerebral creatine deficiency syndromes. Mol Genet Metab 2013;109:260-8.

3. Item $C B$, Stöckler-Ipsiroglu S, Stromberger $C$, Mühl A, Alessandrì MG, Bianchi $M C$, et al. Arginine:glycine amidinotransferase deficiency: the third inborn error of creatine metabolism in humans. Am J Hum Genet 2001;69:1127-33.

4. Stöckler S, Isbrandt D, Hanefeld F, Schmidt B, von Figura K. Guanidinoacetate methyltransferase deficiency: the first inborn error of creatine metabolism in man. Am J Hum Genet 1996;58:914-22.

5. Mercimek-Andrews S, Salomons GS. Creatine deficiency syndromes. In: Adam MP, Ardinger HH, Pagon RA, Wallace SE, eds. GeneReviews ${ }^{\circledR}$. Seattle (WA): University of Washington, 2015.

6. Freed $D$, Aldana $R$, Weber JA, Edwards JS. The sentieon genomics tools - a fast and accurate solution to variant calling from nextgeneration sequence data. bioRxiv 2017, in press.

7. McLaren W, Pritchard B, Rios D, Chen Y, Flicek P, Cunningham F. De- riving the consequences of genomic variants with the Ensembl API and SNP effect predictor. Bioinformatics 2010;26:2069-70.

8. Zerbino DR, Achuthan P, Akanni W, Amode MR, Barrell D, Bhai J, et al. Ensembl 2018. Nucleic Acids Res 2018;46:D754-61.

9. Plagnol V, Curtis J, Epstein M, Mok KY, Stebbings E, Grigoriadou S, et al. A robust model for read count data in exome sequencing experiments and implications for copy number variant calling. Bioinformatics 2012;28:2747-54.

10. Landrum MJ, Lee JM, Benson M, Brown G, Chao C, Chitipiralla $S$, et al. ClinVar: public archive of interpretations of clinically relevant variants. Nucleic Acids Res 2016;44:D862-8.

11. Mercimek-Andrews S, Salomons GS. Creatine deficiency syndromes. In: Adam MP, Ardinger HH, Pagon RA, Wallace SE, eds. GeneReviews ${ }^{\circledR}$. Seattle (WA): University of Washington, 2009.

12. Salomons GS, van Dooren SJ, Verhoeven NM, Cecil KM, Ball WS, Degrauw TJ, et al. X-linked creatine-transporter gene (SLC6A8) defect: a new creatine-deficiency syndrome. Am J Hum Genet 2001;68:1497500.

13. van de Kamp JM, Mancini GM, Salomons GS. X-linked creatine transporter deficiency: clinical aspects and pathophysiology. J Inherit Metab Dis 2014;37:715-33.

14. Clark AJ, Rosenberg EH, Almeida LS, Wood TC, Jakobs C, Stevenson $\mathrm{RE}$, et al. X-linked creatine transporter (SLC6A8) mutations in about $1 \%$ of males with mental retardation of unknown etiology. Hum Genet 2006;119:604-10.

15. deGrauw TJ, Cecil KM, Byars AW, Salomons GS, Ball WS, Jakobs C. The clinical syndrome of creatine transporter deficiency. Mol Cell Biochem 2003;244:45-8.

16. Wang O, Yang J, Liu Y, Li X, Luo F, Xie J. A novel SLC6A8 mutation associated with intellectual disabilities in a Chinese family exhibiting creatine transporter deficiency: case report. BMC Med Genet 2018;19:193.

17. Mancardi MM, Caruso U, Schiaffino MC, Baglietto MG, Rossi $A$, Battaglia FM, et al. Severe epilepsy in X-linked creatine transporter defect (CRTR-D). Epilepsia 2007;48:1211-3.

18. Pyne-Geithman GJ, deGrauw TJ, Cecil KM, Chuck G, Lyons MA, Ishida $Y$, et al. Presence of normal creatine in the muscle of a patient with a mutation in the creatine transporter: a case study. Mol Cell Biochem 2004;262:35-9.

19. Stöckler-Ipsiroglu S, Mercimek-Mahmutoglu GS, Salomons GS. Creatine deficiency syndromes. In: Saudubray JM, van den Berghe G, Pagon RA, Walter JH, eds. Inborn metabolic diseases. Berlin: SpringerVerlag Berlin Heidelberg, 2012.

20. Braissant $\mathrm{O}$, Bachmann $\mathrm{C}$, Henry $\mathrm{H}$. Expression and function of AGAT, GAMT and CT1 in the mammalian brain. Subcell Biochem 2007;46:67-81. 